\title{
- COVID-19: Knowledge, Attitude, Practice in Malaysia
}

IJCRR
Section: Healthcare
ISI Impact Factor
$(2019-20): 1.628$
IC Value (2019): 90.81
SJIF (2020) = 7.893
CC) (9)

\section{Rafidah Elias ${ }^{1}$, Girthanah A/P Vigayan², Hamsaa Varrthini A/P Mohana Kumar², Mauna Sree A/P Sevanesan², Ragavinotini A/P Rajan², Savitha A/P Gurumoorthy²}

\begin{abstract}
'Department of Family Medicine, Faculty of Medicine and Health Sciences, University Malaysia Sarawak (UNIMAS), Kota Samarahan, Malaysia; 'Faculty of Medicine and Health Sciences, University Malaysia Sarawak (UNIMAS), University Malaysia Sarawak, Kota Samarahan, Malaysia.
\end{abstract}

\section{ABSTRACT}

Background: Malaysia is no exception to the COVID-19 pandemic, and to date, there is no specific treatment to cure the disease, and the vaccine is still not available. Hence, to stress the importance of practising protective measures.

Objective: This study intended to examine the knowledge, attitude, and practice towards COVID-19 and its preventive measures among Malaysian amid the CMCO (Conditional Movement Control Order) during the COVID-19 pandemic in Malaysia.

Methods: This cross-sectional study was conducted online among Malaysians aged 18 years old and above from May to June 2020 using a self-developed questionnaire through snowball sampling.

Results: A total of 571 respondents were analyzed. The average age was 26 years old, and monthly income was RM1500, about half were females (57.8\%), had education level to undergraduate $(58.1 \%)$, one-third were Indians (34.7\%), one-fifth were Malays (23.6\%), one-third from Sarawak (31.2\%), and one-fifth from Selangor $(25.0 \%)$. The correct rate for all three outcome domains was high, $83 \%$ for knowledge, $85 \%$ for attitude, and $86 \%$ for practice. Few respondents still holding the myths regarding COVID-19. No significant factors contributed to the knowledge score. Factors that contributed to higher attitude scores were monthly income and employment status. Factors that contributed to higher practice scores were female, Chinese, and medical employees. The higher the knowledge score, the higher the attitude score and practice score.

Conclusions: Malaysians discerned and optimistic about COVID-19, its preventive measures, and the implementation of MCO. They had confidence with the government in combating COVID-19 and were practising preventive measures.

Key Words: Attitude, COVID-19, Knowledge, Malaysia, Practice

\section{INTRODUCTION}

Coronavirus disease (COVID-19) is a pandemic, affecting 216 countries, with 8061550 confirmed cases and 440290 confirmed deaths globally. ${ }^{1-5}$ Malaysia is the earliest to declare positive cases among the Southeast Asian country. $5,6,7$ Following the tremendous increase in COVID-19 cases in Malaysia, the government has enforced the Movement Control Order (MCO). It commenced on 18th March 2020, endeavouring containment and mitigation of the COVID-19 cases to flatten the curve of positive cases, thus lighten the burden of health care systems in Malaysia. ${ }^{7-10}$

The success of MCO permitted the country to substitute MCO to Conditional Movement Control Order (CMCO), whereby more restrictions were lifted. However, the community is demanded to adhere to the Standard Operation
Procedure (SOP) and continuously habituate the new normal to hinder another surge of COVID-19 cases., ${ }^{3,9}$ This new normal comprised wearing a face mask, washing hands frequently with hand sanitiser or soap and water, social distancing, and avoiding crowded places. ${ }^{6}, 11$ These practices demand the community to transform their behaviour, which relies on their knowledge and attitude towards the disease and its preventive measures. ${ }^{12-17}$ A prior study by Azlan et $\mathrm{al}^{2}{ }^{2}$ had demonstrated a decent level of knowledge concerning COVID-19 among Malaysian before the implementation of $\mathrm{MCO}{ }^{2}$

This current study intended to re-examine the level of knowledge, attitude and practices regarding COVID-19 encompass sign and symptoms, mode of transmission and preventive measures, among adult Malaysian using self-de-

\section{Corresponding Author:}

Rafidah Elias, Department of Family Medicine, Faculty of Medicine and Health Sciences, University Malaysia Sarawak (UNIMAS), Kota Samarahan, Malaysia; Telephone:+6012-8868485; Email: erafidah@unimas.my

ISSN: 2231-2196 (Print)

Received: 09.10 .2020
ISSN: 0975-5241 (Online)

Revised: 06.11 .2020
Accepted: 08.12.2020
Published: 23.02 .2021 
veloped questionnaire during the implementation of CMCO. It covers attitudes and practices toward preventive measures, which was not examined in the previous study. Additionally, it includes the practice of proper usage of face mask, myths, and panic buying in the community during $\mathrm{CMCO}$.

This study is imperative to reassess the persistence of knowledge, attitude, and practices regarding COVID-19 and its preventive measures toward the recovery phase of the COVID-19 pandemic in Malaysia. Data gained from this study would gauge the effectiveness and sustainability of health education and promotion delivered to the public via social media and mass media. Additionally, it helps to identify a group of communities with a low level of knowledge, attitude, and practices that require more attention in terms of the provision of information regarding COVID-19. This study would also provide the data concerning compliances to preventive measures, which is the paramount important at the moment to conquer the COVID-19. Furthermore, this study also examines the myths and disinformation regarding COVID-19 and its preventive measures that would be beneficial to be identified and clarified by authorities to avoid scepticism in the community.

\section{MATERIALS AND METHODS}

\section{Study design and population}

This study was a cross-sectional study. It was conducted online among adult Malaysian aged 18 years old and above from May 2020 until June 2020.

\section{Sampling method}

The Snowball sampling method was used to recruit a total of 580 study samples, surpassed a total calculated sample size, which was 460 . The sample size was obtained from the Openepi Application for calculation of sample size with an unknown total number of study population and frequency of study sample. The calculated sample size, with a $95 \%$ confidence interval was 384 . With the addition of a $20 \%$ nonresponse rate, the total calculated sample size was 460 . A bilingual version of Malay and English online survey was created using google form and distributed through researchers' social network via social media to those who fulfilled the criteria, who then shared the link to others. The inclusion criteria include adult Malaysian aged 18 years old and above who able to understand English or Malay. Whereas, the exclusion criterion was medical students of UNIMAS because they were given the information regarding COVID-19 in the educational platform eLEAP UNIMAS and were involved with other studies regarding COVID-19.

\section{Study instrument}

The study instrument was an online survey form. It incorporates the information regarding the study, respondent's consent form, sociodemographic data collection form, and self-developed questionnaire of the Knowledge, Attitude, and Practice (KAP) towards the COVID-19. The KAP questionnaire was validated through a pilot study. It was conducted among 46 undergraduate students of UNIMAS, which was $10 \%$ of the calculated sample size. Half of the sample were medical students, and another half were nonmedical students. The Cronbach alpha for Knowledge, Attitude, and Practice scales were 0.723, 0.808, and 0.723, respectively.

Sociodemographic data comprises of age, gender, race, religion, marital status, highest education level, employment status, monthly income, and current place of staying. Knowledge domain comprises of 18 items covering signs and symptoms (4 items), high-risk groups (5 items), mode of transmission (3 items), availability of vaccine (1 item), and preventive measures towards COVID-19 (5 items). The possible response was a dichotomous, 'yes' or 'no' with one score given for each correct answer and zero for each incorrect answer. Accordingly, the total score ranges from ' 0 ' to ' 18 ', whereby the higher score indicates a higher level of knowledge. Attitude domain comprises of 12 items. It includes attitude towards the preventive measures ( 8 items), abide quarantine order ( 1 item), willingness to meet a person who had tested positive despite declared cured (1 item), implementation of MCO (Movement Control Order) (1 item), and confidence with government at combating the COVID-19 (1 item). The possible response was a Likert scale, ranging from ' 1 ' to ' 5 ' from 'strongly disagree' to 'strongly agree.' Accordingly, the total score ranges from ' 12 ' to ' 60 ', whereby the higher score indicates a more positive attitude. Practice scale comprises of 10 items covering practices of preventive measures (9 items) and disinformation regarding COVID-19 (1 item). The possible response was a Likert scale, ranging from ' 1 ' to ' 5 ' from 'strongly disagree' to 'strongly agree.' Accordingly, the total score ranges from ' 10 ' to ' 50 ', whereby the higher score indicates practising more preventive measures. All three scales contain both positive and negative statements, and all negative statements have been given a reversed score before analysis.

\section{Data analysis}

Data in an excel spreadsheet was revised and exported to Statistical Package for Social Sciences (SPSS), version 18, then analyzed using multiple linear regression. The P-value of less than 0.05 was considered a significant finding.

\section{Ethical consideration}

The Medical Ethical Committee of UNIMAS has approved the study (Reference number: UNIMAS/NC-21.02/03-02 Jld.4 (65)). 


\section{RESULTS}

\section{Sociodemographic background}

A total of 571 respondents were analyzed. The average age was 26 years old $(\mathrm{IQR}=18$, range $=18-73)$ and monthly income was $\mathrm{RM} 1500(\mathrm{IQR}=4000$, range $=0-24$ 000). More than half were females $(57.8 \%)$, about one-third were Indian (34.7\%), followed by Malays (23.6\%) and Chinese (14.4\%). About one-third were Hindu (31.3\%), Christian (30.8\%) and Muslim (28.2\%). More than half have the highest education level until undergraduate $(58.1 \%)$, followed by pre-university $(16.6 \%)$ and postgraduate and masters (14.5\%). Almost two-thirds were single $(60.4 \%)$. Almost half were students $(41.3 \%)$, followed by the non-medical employee $(31.3 \%)$ and medical employee (18\%). About one-third of them were from Sarawak (31.2\%), followed by Selangor $(25.0 \%)$, and another half were from other states throughout Malaysia. Detail displays in Table 1.

\section{Sources of knowledge concerning COVID-19}

Most of the respondents acquired knowledge concerning COVID-19 from social media (81.8\%), mass media (80.9\%), and Ministry of Health, Malaysia website (74.1\%). Additionally, more than half acquired knowledge from friends and family $(60.1 \%)$ and the World Health Organization website $(52 \%)$. Detail displays in Table 2.

\section{Knowledge, attitude and practice towards COVID-19}

As shown in Table 3, the average score for the knowledge was $15(\mathrm{IQR}=3$, range $=5-18)$, the attitude was 51 $(\mathrm{IQR}=10$, range $=27-60)$, and the practice was $43(\mathrm{IQR}=7$, range $=16-50)$. Accordingly, the overall correct answer rate for the knowledge was $83 \%(15 / 18 * 100)$, the positive attitude was $85 \%(51 / 60 * 100)$, and the correct practice was $86 \%(43 / 50 * 100)$.

As shown in Table 4, most of the respondents realized that the elderly (95.6\%) and individuals with chronic illnesses (93.7\%) are high-risk groups of getting severe COVID-19 disease. Additionally, they realized that people who are less than 1 meter apart from positive cases who are coughing or sneezing could get infected $(87.7 \%)$. Furthermore, they also realized that a person who touches their eye, nose, or mouth after in contact with an infected object or surface (96\%) could get infected. Likewise, most aware of the need to self-quarantine themselves once returned from overseas (94\%), avoid crowded places (98.4\%), practice cough and sneeze etiquette $(94.7 \%)$, and wear a face mask in public areas $(71.3 \%)$.

As shown in Table 5, most had a positive attitude towards preventive measures. They believe the importance of selfquarantine once returned from overseas (94.6\%), avoiding crowded places $(96.4 \%)$, social distancing (63.1\%), prac- tising cough and sneeze etiquette (72.7\%), washing hands regularly $(96.1 \%)$, and wearing a face mask in public places $(90.2 \%)$. Furthermore, most agreed with the implementation of $\mathrm{MCO}(89.5 \%)$ and had confidence in the government to overcome COVID-19 (77.4\%)

As shown in Table 6, most undertaken preventive measures such as avoid crowded places (92.3\%), wash hands regularly (93\%), wear a face mask in public places (93.2\%), avoid touching face while wearing a face mask (76.7\%), discard the face mask immediately in the closed bin once removed $(86.5 \%)$, wash hands immediately after removing the face mask (90.1\%), and keep social distancing (93.2\%)

These findings demonstrated that Malaysians were discerned about COVID-19 and its preventive measures, had optimistic attitudes and undertaken the preventive measures to break the transmission of COVID-19 in the community. Despite that, few were still holding to the myths and disinformation regarding COVID-19 and its preventive measures. Almost half of the respondents thought COVID-19 could spread from pet to human (48\%), and more than half thought COVID-19 could spread through food or food packaging $(59 \%)$. Moreover, about half never disinfect their handphone $(46.7 \%)$, more than half never disinfect their doorknob (54.6\%), sprayed or applied disinfectant fluid on their body to prevent COVID-19 (54.1\%), drank warm water to prevent COVID-19 (59.9\%) and took a hot bath to prevent COVID-19 (44.7\%). Besides, most would avoid encounters with people who had tested positive despite declared cured of COVID-19 (78.8\%) and had purchased the essentials in larger quantities than usual $(75.8 \%)$.

\section{Association between total score of knowledge and sociodemographic background}

There was a significant linear relationship between age and total score of knowledge $(\mathrm{P}<0.001)$. Those with ten years older have a higher total score of knowledge by $0.3(95 \%$ CI: 0.17-0.44). There was a statistically significant difference in the total score of knowledge between those staying in West Malaysia and Sarawak. Those staying in West Malaysia have a lower total score of knowledge by 0.58 (95\% CI: 1.03-0.14) as compared to those staying in Sarawak. There was a statistically significant difference in the total score of knowledge between Indians and others compared to Malay $(\mathrm{P}<0.001$ and $\mathrm{P}<0.001$, respectively). Indians have a lower total score of knowledge by 0.75 (95\% CI: 1.15-0.35) and other races lower by 0.99 (95\% CI: 1.46-0.52) as compared to Malay. There was a significant difference in the total score of knowledge between a group of undergraduate and postgraduate compared to a group of pre-university $(\mathrm{P}<0.001$ and $\mathrm{P}<0.001$ respectively). A group of undergraduates have a higher total score of knowledge by 1.06 (95\% CI: 0.64-1.47) and a group of postgraduates and masters by 1.07 (95\% CI: $0.56-1.57)$ as compared to a group of pre-university. There 
was a significant difference between a group of medical employees and a group of unemployed $(\mathrm{P}=0.002)$. A group of medical employees have a higher total score of knowledge by 0.72 (95\% CI: $0.27-1.17)$ as compared to a group of unemployed. Therefore, a total score of knowledge affected by age, current place of staying, races, highest education level, and employment status. Detail displays in table 4.

\section{Association between total score of attitude and sociodemographic background}

There was a significant difference in the total score of attitudes between respondents with monthly income RM 5000- RM9999 and respondents with monthly income less than RM5000 ( $\mathrm{P}=0.009)$. Those with monthly income RM5000- RM9999 have a higher total score of attitudes by 1.70 (95\% CI: $0.43-2.98)$ as compared to those with monthly income less than RM5000. There was a significant difference in the total score of attitudes between students and unemployed $(\mathrm{P}=0.005)$. Students have a higher total score of attitudes by 1.45 (95\% CI: $0.46-2.44)$ as compared to the unemployed. Therefore, the total score of attitudes affected by monthly income and employment status. Detail displays in table 5.

\section{Association between total score of practice and sociodemographic characteristics}

There was a significant difference in the total score of practices between females and males $(\mathrm{P}=0.003)$, whereby females have a higher total score of practices by 1.84 (95\% CI: 1.016-2.664). There was a significant difference in the total score of practices between Chinese and Malays ( $\mathrm{P}<0.001)$, whereby the Chinese have a higher total score of practice by 1.58 (95\% CI: 0.54-2.62). There was a significant difference in the total score of practices between medical employees and unemployed $(\mathrm{P}<0.001)$, whereby the medical employees have a higher total score of practices by 2.24 (95\% CI: 1.19-3.30). Therefore, the total score of practice is affected by gender, race, and employment status. Detail displays in table 6.

\section{Relationship between the level of knowledge, attitude and practice towards COVID-19}

There was a significant linear relationship between the total score of knowledge and total score of attitudes $(p<0.001)$. Those with 1 unit higher in the total score of knowledge have 0.822 units higher in the total score of attitudes $(95 \%$ CI: $0.084,0.137)$. There is a significant linear relationship between the total score of attitudes and a total score of practice $(\mathrm{p}<0.001)$. Those with 1 unit higher in the total score of attitudes have 0.223 units higher in the total score of practices (95\% CI: 0.190,0.367). Therefore, higher knowledge regarding COVID-19 and its preventive measures contribute to higher attitudes and practices towards its preventive measures. Detail displays in tables 7, 8, and 9.

\section{DISCUSSION}

COVID-19 has attracted the attention of people worldwide since it has affected the population in many aspects. However, there is no vaccine nor the specific medications available to eliminate and cure the COVID-19. Therefore, preventive measures are the key to combat COVID-19, which depends primarily on community adherence to preventive measures. Many studies have shown that practice of preventive measures determined by the knowledge and attitude of the community. Therefore, the authorities obliged to monitor the knowledge, attitude, and practices towards COVID-19, notably the preventive measures among the Malaysian community. Additionally, identifying the attributes to the lower level of knowledge, attitude, and practices would be beneficial for proper planning of any strategies to ensure the standard level of knowledge, attitude, and practice achieved.

Our findings have shown that the Malaysians are educated about COVID-19, and its preventive measures (correct rate was $83 \%$ ), have optimistic attitudes (85\%) and practising the correct preventive measures $(86 \%)$ to break the transmission of COVID-19 in the community. These findings correspond to a study done by Azlan et al. ${ }^{2}$ among Malaysians. It reported Malaysians to have a high level of knowledge regarding COVID-19 (correct rate was 80.5\%), held sound attitudes, and practising preventive measures such as avoiding crowds $(83.4 \%)$ and practising proper hand hygiene (87.8\%). However, our findings have shown that there were more people wearing face masks when going out $(93.2 \%)$ compared to the previous study done during the initial phase of MCO, which was $51.2 \%{ }^{2}$ This finding related to the accessibility of the face mask, whereby the community could easily purchase it from pharmacies and retail shops compared to the initial phase of the pandemic. A study was done by Praharaj M. also found a high level of knowledge $(80.28 \%)$ regarding COVID-19 among participants from Odisha, however, the level of attitude was lower $(58.03 \%){ }^{21}$

Factors contributed to higher knowledge scores were increasing age $(\mathrm{P}<0.001)$ and staying in Sarawak compared to West Malaysia $(\mathrm{P}=0.011)$. Other factors that contributed to higher knowledge scores were Malays compared to Indian and others $(\mathrm{P}<0.001$ and $\mathrm{P}<0.001)$. Likewise, undergraduate and postgraduate or master had higher knowledge scores compared to pre-university $(\mathrm{P}<0.001$ and $\mathrm{P}<0.001)$. Also, medical employees had higher knowledge scores compared to the unemployed $(\mathrm{P}=0.002)$. However, the discrepancy in scores for all attributes was about 1-2 score only. Therefore, although the discrepancy in scores was statistically significant, it was too little to be considered significant. This study failed to demonstrate the significant attribution of factors such as age, residency, socioeconomic status, gender and education level to knowledge score as shown in other studies done in China, Tanzania, Egypt and Sudan. ${ }^{1,18,19}$ 
Factors contributed to higher attitude scores were monthly income of RM 5000- RM9999 as compared to monthly income less than RM $5000(\mathrm{P}=0.009)$ and student compared to unemployed $(\mathrm{P}=0.005)$. The discrepancy between the total score of attitudes was between 1-3. These findings correspond to other studies done in China and Bangladesh, whereby the higher the education and the income, the more positive their attitude. ${ }^{19}$

Factors attributed to higher practice scores were female ( $\mathrm{P}=0.003)$, Chinese compared to Malay $(\mathrm{P}<0.001)$, and medical employees compared to unemployed $(\mathrm{P}<0.001)$. The discrepancy between the score was between 1-3. The findings of female attributed to better practice than male correspond to other studies done in China and Sudan. ${ }^{10,19}$ Since the COVID-19 pandemic, there have been some myths and disinformation regarding COVID-19 spreading in the community. These might lead to confusion and malpractices in the community. Therefore, the WHO (World Health Organization) has taken action to debunked most of it through the WHO website. ${ }^{11}$ Despite that, our findings have shown that a significant number of Malaysians were still holding on a myth about COVID-19. About one-third of respondents thought that COVID-19 could spread from pet to human (31.3\%), and more than two-thirds thought that it could spread from food or food packaging $(72.5 \%)$. More than one-third of respondents had sprayed or applied the disinfectant fluid on their body to prevent COVID-19 (39\%), exposed themselves to sunlight (34.8\%), drank warm water to prevent COVID-19 (49\%) and took a hot bath to prevent COVID-19 (32.6\%).

Moreover, most of the respondents responded that they would avoid meeting a person who had COVID-19, although they have cured $(78.8 \%)$. This finding verified the statement by CDC (Centre for Disease Control and Prevention), which stated that the possible group that might stigmatize during the COVID-19 pandemic were the people who had COVID-19, had recovered, or had released from quarantine. These groups of people might be discriminated in the form of avoided or rejected by other people, turned down from healthcare, education, housing, or employment and, verbally and physically abused. Stigmatized persons and even the communities they live in can have adverse effects on their emotional, mental, and physical wellbeing. ${ }^{4}$

Furthermore, more than half of the respondents confessed that they had purchased the essentials in larger quantities than usual (53.8\%). This finding justified the statement regarding the socioeconomic implications of the COVID-19 pandemic worldwide, whereby the food sector was among few sectors that have been under pressure as a result of people's panic buying and stocking up food supplies. ${ }^{13}$ Nevertheless, most of the respondents agreed with the implementation of MCO (Movement Control Order) to break the transmission of COVID-19 (89.5\%) and assured that Malaysia would con- quer the COVID-19 (77.4\%). These correspond to the previous study, which stated that the participants held positive attitudes toward the achievement of control of COVID-19 (83.1\%) and the capability of Malaysia to vanquish the disease $(95.9 \%){ }^{2}$

Our findings have shown that there was a significant interrelationship between knowledge score and attitude score with practice score. The higher the knowledge score, the higher the attitude score and the practice score. This finding corresponds to the study done in China and Saudi Arabia, whereby higher knowledge scores are associated with lower negative attitudes and practising preventive measures. ${ }^{19,20}$

\section{LIMITATIONS}

The sampling of respondents was performed through convenience sampling, which was a snowball sampling method, and the survey form was distributed through researchers' social networks via social media platforms like WhatsApp, Facebook, and Instagram. Therefore, the underprivilege population that does not have access to the internet and not using social media platforms were unable to participate in the study. Random sampling is required to ensure that the findings can be generalized to the population..$^{18-22}$ The questionnaire used to measure Knowledge, Attitude, and Practice towards COVID-19 and its preventive measures were self- developed. It was developed based on the information obtained from the Ministry of Health (MOH) website, World Health Organization (WHO) website, online news, previous studies, peer review, and feedback from the pilot study, without subjected to proper validation process due to the limited time to conduct the study. Although it has been tested in a pilot study to improve the reliability of the questionnaire, further processes are required to validate the questionnaire thoroughly.

Lastly, the possibility of respondents giving socially desirable responses is inevitable.

\section{CONCLUSIONS}

In summary, this study has contributed to additional information for further understanding of the knowledge, attitudes, and practices towards COVID-19 among Malaysians. It has demonstrated that Malaysians are discerned about COVID-19 and its preventive measures, have optimistic attitudes towards the preventive measures, implementation of MCO and the ability of Malaysia to win the battle against COVID-19, and practising preventive measures as demanded by the authorities. However, a particular group of people were still holding on to the myths and disinformation regarding COVID-19; thus, authorities obliged to clarify the issues to 
avoid malpractice and negative consequences related to it. Furthermore, particular groups of people have been identified to have a lower level of knowledge, attitude, and practice towards COVID-19. Hence, the particular actions must be taken to ensure the achievement of the standard level of knowledge, attitude, and practice towards COVID-19 and its preventive measures among different groups of people in the community to safeguard the country from COVID-19. A continuous effort from the authorities is required to maintain a gratifying level of knowledge, attitude, and practice towards COVID-19 and its preventive measures among Malaysians.

\section{Supplementary Information}

Supplementary information accompanies this paper in a PDF format attached.

\section{Abbreviations}

COVID-19: Coronavirus Disease 2019; KAP: Knowledge, Attitude and Practice; FMHS: Faculty of Medicine and Health Sciences; WHO: World Health Organization; UNIMAS: Universiti Malaysia Sarawak; SPSS: Statistical Package for Social Sciences (SPS).

\section{ACKNOWLEDGMENTS}

We would like to thank the participants who voluntarily participated in this study and University Malaysia Sarawak (UNIMAS), who supported this study. Authors acknowledge the immense help received from the scholars whose articles are cited and included in references to this manuscript. The authors are also grateful to authors/ editors/ publishers of all those articles, journals and books from where the literature for this article has been reviewed and discussed.

Authors' Contributions: The questionnaire was self-designed and distributed online to the study population by all authors. Rafidah Elias provided guidance throughout the study, reviewed the manuscript, and submitted the article.

Funding: This study was not funded.

Ethics Approval and Consent to Participate: Ethics approval from the Ethical Committee of Faculty of Medicine and Health Sciences, UNIMAS, Sarawak attained. (Ref: UNIMAS/NC-21.02/03-02 Jld.4 (65)). All participants consented to participate voluntarily in the study.

Consent for Publication: Not applicable

Conflict of Interest: The authors have no conflict of interests to proclaim.

Authors Detail: Rafidah Elias, UNIMAS. Girthanah A/P Vigayan, UNIMAS. Hamsaa Varrthini A/P Mohana Kumar, UNIMAS. Mauna Sree A/P Sevanesan, UNIMAS. Ragavinotini A/P Rajan, UNIMAS. Savitha A/P Gurumoorthy, UNIMAS.

\section{REFERENCES}

1. Abdelhafiz AS, Mohammed Z, Ibrahim ME, Ziady HH, Alorabi M, Ayyad M, et al. Knowledge, perceptions, and attitude of Egyptians towards the novel coronavirus disease (COVID-19). J Comm Health 2020;21:1-10.

2. Azlan AA, Hamzah MR, Sern TJ, Ayub SH, Mohamad E. Public knowledge, attitudes and practices towards COVID-19: A crosssectional study in Malaysia. PloS One 2020;15(5):e0233-668.

3. Ghani A. Get ready for the 'new normal', post-MCO. The Star Online [Internet]. 2020; Available from https://www.thestar. com.my/news/nation/2020/05/09/with-mco-phase-4-endingsoon-will-life-in-malaysia-return-to-normal

4. Centres for Disease Control and Prevention. Reducing Stigma | CDC. In National Center for Immunization and Respiratory Diseases (NCRID), Division of Viral Diseases; 2020.

5. Culp Jr WC. Coronavirus Disease 2019: In-Home Isolation Room Construction. J Comm Heal Pract 2020;14(6):e012-18.

6. Y LM. Covid-19: What does the "new normal" mean? The Star Online 2020 May 21.

7. Awg Mahmud AB. Not lockdown but forced social distancing to save Malaysia. St Med Gr Berh. 2020;3(2):32-34.

8. Hussain A, Garima T, Singh BM, Ram R, Tripti RP. Knowledge, attitudes, and practices towards COVID-19 among Nepalese Residents: A quick online cross-sectional survey. Asi J Med Sci 202011(3):6-11.

9. Mazwin Nik Anis ZK. More restrictions lifted but with SOP. The Star Online 2020.

10. Mohamed A, Elhassan E, Mohamed AO, Mohammed AA, Mahgoop MA, Sharif ME, Bashir MI, Abderlahim RB, Idriss WI, Malik EM. Knowledge, attitude and practice of the Sudanese people towards COVID-19: Asi J Med Sci. 2020;09(3):16-18.

11. Nash DB. COVID-19:Myth busters. Asi J Med Sci Tech. 2008;33(7):378.

12. New Straits Time. Malaysia records first two Covid-19 deaths; cases soar to 673. New Straits Times 2020.

13. Nicola M, Alsafi Z, Sohrabi C, Kerwan A, Al-Jabir A, Iosifidis C, Agha M, Agha R. The socio-economic implications of the coronavirus pandemic (COVID-19): A review. Int J Surg 2020 Jun;78(12):185-188.

14. Pfordten D, Razak A. Covid-19: Current situation in Malaysia (updated daily). The Star Online 2020.

15. Sipalan J, Holmes S. Malaysia confirms first cases of coronavirus infection. Reuters. Archived from the original on. 2020 Jan 25;18.

16. Shien LS. The 'new normal' Post COVID-19 - BW Hotelier 2020.2020;12(4):45-48.

17. Thompson TL. Encyclopedia of health communication. Sage Publications; 2014 Apr 18.

18. Ferdous MZ, Islam MS, Sikder MT, Mosaddek AS, ZegarraValdivia JA, Gozal D. Knowledge, attitude, and practice regarding COVID-19 outbreak in Bangladesh: An online-based crosssectional study. PloS one. 2020 Oct 9;15(10):e0239254.

19. Zhong BL, Luo W, Li HM, Zhang QQ, Liu XG, Li WT, Li Y. Knowledge, attitudes, and practices towards COVID-19 among Chinese residents during the rapid rise period of the COVID-19 outbreak: a quick online cross-sectional survey. Int $\mathrm{J}$ Biol 2020;16(10):174-175.

20. White S, Omer M, Nazeer Mohammad G. Knowledge, attitude and practice on prevention of airborne and droplet infections during the outbreak of coronavirus among the college students in the University of Bisha, Saudi Arabia. Int J Curr Res Rev. 2020;11(04):20773-20776.

21. Praharaj M, Tanaya K, Das SR. Knowledge and attitude towards covid 19 among Indian residents: A cross-sectional study. Int J Curr Res Rev. 2020;12(24):211-216. 
22. White S, Omer M, Nazeer Mohammad G. Knowledge, attitude and practice on prevention of airborne and droplet infections during the outbreak of coronavirus among the college stu- dents in University of Bisha, Saudi Arabia. Int J Curr Res Rev 2020;11(04):20773-6.

Table 1: Sociodemographic background of respondents $(\mathrm{N}=571)$

\begin{tabular}{|c|c|c|c|}
\hline Variable & n (\%) & Median (IQR) & Mean (SD) \\
\hline Age (Year) & - & $26(18)^{\underline{a}}$ & $33(13)$ \\
\hline Monthly Income (RM) & - & $1500(4000) \underline{a}$ & $2596(3393)$ \\
\hline $\begin{array}{l}\text { Gender } \\
\text { Male } \\
\text { Female }\end{array}$ & $\begin{array}{l}241(42.2) \\
330(57.8)\end{array}$ & & \\
\hline $\begin{array}{l}\text { Race } \\
\text { Malay } \\
\text { Chinese } \\
\text { Indian } \\
\text { Iban } \\
\text { Bidayuh } \\
\text { Others }\end{array}$ & $\begin{array}{l}135(23.6) \\
105(18.4) \\
198(34.7) \\
51(8.9) \\
27(4.7) \\
55(9.6)\end{array}$ & & \\
\hline $\begin{array}{l}\text { Religion } \\
\text { Islam } \\
\text { Buddha } \\
\text { Hindu } \\
\text { Christian } \\
\text { Others }\end{array}$ & $\begin{array}{c}161(28.2) \\
46(8.1) \\
179(31.3) \\
176(30.8) \\
9(1.6)\end{array}$ & & \\
\hline $\begin{array}{l}\text { Highest Education Level } \\
\text { No education } \\
\text { Secondary school } \\
\text { Pre-university } \\
\text { Undergraduate } \\
\text { Postgraduate/Masters } \\
\text { PhD }\end{array}$ & $\begin{array}{c}1(0.2) \\
47(8.2) \\
95(16.6) \\
332(58.1) \\
83(14.5) \\
13(2.3)\end{array}$ & & \\
\hline $\begin{array}{l}\text { Marital Status } \\
\text { Single } \\
\text { Married } \\
\text { Divorced } \\
\text { Others }\end{array}$ & $\begin{array}{c}345(60.4) \\
215(37.7) \\
6(1.1) \\
5(0.9)\end{array}$ & & \\
\hline $\begin{array}{l}\text { Employment Status } \\
\text { Unemployed } \\
\text { Student } \\
\text { Employed (Medical) } \\
\text { Employed (Non-medical) }\end{array}$ & $\begin{array}{l}53(9.3) \\
236(41.3) \\
103(18.0) \\
179(31.3)\end{array}$ & & \\
\hline $\begin{array}{l}\text { Current Residency } \\
\text { Johor } \\
\text { Kedah } \\
\text { Kelantan } \\
\text { Kuala Lumpur } \\
\text { Labuan } \\
\text { Melaka } \\
\text { Negeri Sembilan } \\
\text { Pahang } \\
\text { Perak } \\
\text { Pulau Pinang } \\
\text { Putrajaya } \\
\text { Sabah } \\
\text { Sarawak } \\
\text { Selangor } \\
\text { Seremban } \\
\text { Terengganu } \\
\text { Unknown }\end{array}$ & $\begin{array}{c}19(3.3) \\
50(8.8) \\
4(0.7) \\
44(7.7) \\
2(0.4) \\
7(1.2) \\
11(1.9) \\
11(1.9) \\
26(4.6) \\
18(3.2) \\
2(0.4) \\
45(7.9) \\
178(31.2) \\
143(25.0) \\
1(0.2) \\
4(0.7) \\
6(1.1)\end{array}$ & & \\
\hline
\end{tabular}

a Skewed to the right; $\mathrm{SD}=$ Standard deviation

$\mathrm{IQR}=$ Interquartile range; $\mathrm{RM}=$ Ringgit Malaysia 
Table 2: Source of knowledge concerning COVID-19 ( $\mathrm{N}=571)$

\begin{tabular}{lc} 
Variables & $\mathbf{n}(\%)$ \\
Social Media & \\
Yes & $467(81.8)$ \\
No & $104(18.2)$ \\
Mass Media & $462(80.9)$ \\
$\quad$ Yes & $109(19.1)$ \\
No & \\
MOH (Ministry of Health Malaysia Website) & $423(74.1)$ \\
$\quad$ Yes & $148(25.9)$ \\
No & \\
Friends and family & $343(60.1)$ \\
Yes & $228(39.9)$ \\
No & \\
WHO (World Health Organization Website) & $297(52.0)$ \\
Yes & $274(48.0)$ \\
No & \\
Others & $39(6.8)$ \\
Yes & $532(93.2)$ \\
No & \\
\hline
\end{tabular}

Table 3: Knowledge, attitude and practice towards COVID-19 ( $\mathrm{N}=571)$

\begin{tabular}{lccc} 
Variable & Number of items & Mean (SD) & Median (IQR) \\
Knowledge & 18 & $14.2(2.2)$ & $15.0(3)^{\mathrm{a}}$ \\
Attitude & 12 & $50.3(6.1)$ & $51.0(10)^{\mathrm{a}}$ \\
Practice & 10 & $42.2(5.2)$ & $43.0(7)^{\mathrm{a}}$ \\
\hline
\end{tabular}

$\mathrm{SD}=$ Standard deviation; ${ }^{\mathrm{a}}=$ Skewed to the left

$\mathrm{IQR}=$ Interquartile range

Table 4: Knowledge regarding COVID-19 ( $=571)$

1. ${ }^{*}$ COVID-19 is a pandemic disease (widespread)

2. ${ }^{*}$ COVID-19 is highly infectious from one individual to another

3. Cough is one of the most common symptoms of COVID-19

4. Runny nose is one of the symptoms of COVID-19

161

28.2

5. Asymptomatic person is unlikely to have COVID-19

6. In general, when will a person show signs and symptoms of COVID-19

370

64.8

7. Children are at risk of serious COVID-19 infection and death

8. Adolescents are at risk of serious COVID-19 infection and death

9. Adult are at risk of serious COVID-19 infection and death

10. Older people are at risk of serious COVID-19 infection and death

11. Individual with chronic illnesses are at risk of serious COVID-19 infection and death

12. A person can be infected with COVID-19 if they are less than 1 meter from a coughing or

13. A person can be infected with COVID-19 if they touch their eye, nose or mouth after touching an infected object or surface

14. COVID-19 can spread from pets to human

15. "COVID-19 can spread through food or food packaging

16. *Antibiotic is a treatment for COVID-19 
Table 4: (Continued)

17. There is no vaccine for COVID-19

18. Self-quarantine at home for 14 days after coming back from overseas can prevent transmission of COVID-19

19. Not going out to crowded places can prevent COVID-19

20. *Maintain social distancing at least 1 meter ( 3 feet) from others, particularly those who are coughing, sneezing and having a fever can prevent COVID-19

$562 \quad 98.4$

21. The practice of proper cough and sneeze etiquette can prevent transmission of COVID-19

22. "The practice of regular handwashing with water and soap is better than using a hand sanitizer to prevent COVID-19

23. The practice of wearing face masks when going out cannot prevent COVID-19

24. Disinfection of frequently touch objects or surfaces cannot prevent transmission of COVID-19

*Not included as part of the total score of knowledge scale

Table 5: Attitudes toward COVID-19 $(\mathrm{N}=571)$

\section{.}

1. I believe, self-quarantine at home for $\mathbf{1 4}$ days after coming back from overseas is important to prevent transmission of COVID-19

2. I believe, not going to crowded places is important to prevent COVID-19

3. I believe, maintain social distancing at least 1 meter ( 3 feet) from others, particularly those who are coughing, sneezing and having a fever is not important to prevent COVID-19

4. I believe, practicing proper cough and sneeze etiquette is not important to prevent transmission of COVID-19

5. I believe, frequent hand wash with water and soap, or hand sanitizer is important to prevent COVID-19

6. I believe, wearing face masks when going out is important to prevent COVID-19

7. I believe, disinfection of frequently touch objects or surfaces is not important to prevent transmission of COVID-19

8. I will isolate myself if I have fever and cough

9. I will accept quarantine in a health facility or quarantine center if I get COVID-19

10. I will avoid meeting a person who is declared cured from COVID-19

11. I do not agree with the implementation of MCO (Movement Control Order) to break the transmission of COVID-19

12. I do not have confidence that Malaysia will win the battle against the COVID-19

\section{Correct}

n

$\%$

$540 \quad 94.6$

550

96.4

360

63.1

415

72.7

549

96.1

515

90.2

430

76.3

546

95.6

549

96.1

121

21.2

511

89.5

442

${ }^{*}$ Not included as part of the total score of attitude scale

Table 6: Practice of preventive measures of COVID-19 ( $\mathrm{N}=571)$

I wash my hands often with water and soap or hand sanitizer

I wear a face mask when I am in public places 
Table 6: (Continued)

Items

Correct

n

$\%$

I clean my hands immediately after removing the face mask

514

90.1

I clean my handphone with soap and water, or disinfectants

304

$53 \cdot 3$

I clean my house's doorknob with soap and water, or disinfectants

259

$45 \cdot 4$

*I spray/ apply the disinfectant fluid on my body to prevent COVID-19

348

61

I expose myself to sunlight/high-temperature environment to prevent COVID-19

372

65.2

*I drink warm water to prevent COVID-19

291

51

*I take a hot bath to prevent COVID-19

385

67.4

I maintain a social distance of a least 1 meter ( 3 feet) away from other people when I am in public places

532

93.2

*I purchase the essentials in a larger quantity than usual

265

46.2

${ }^{*}$ Not included as part of the total score of practice scale

Table 7: Factors associated with total score of knowledge towards COVID-19 among Malaysians (N=571)

\begin{tabular}{|c|c|c|c|c|c|c|c|}
\hline \multirow[t]{2}{*}{ Variables } & \multicolumn{3}{|c|}{ SLR $^{a}$} & \multicolumn{4}{|c|}{$\mathbf{M L R}^{\mathrm{b}}$} \\
\hline & $b^{\mathrm{c}}$ & $(95 \% \mathrm{CI})$ & $P$ value & $\operatorname{Adj} . b^{\mathrm{d}}$ & $(95 \% \mathrm{CI})$ & $t$-stat & $P$ value \\
\hline Age (years) & 0.028 & $(0.014,0.041)$ & $<0.001$ & 0.031 & $(0.017,0.044)$ & 4.497 & $<0.001$ \\
\hline \multicolumn{8}{|l|}{ Monthly income } \\
\hline Less than $\mathrm{RM}_{5000}$ & 1 & & & & & & \\
\hline RM50oo-RM9999 & 0.59 & $(0.12,1.059)$ & 0.014 & & & & \\
\hline More than RMioooo & 1.571 & $(0.713,2.428)$ & $<0.001$ & & & & \\
\hline \multicolumn{8}{|l|}{ Current residency } \\
\hline Sarawak & 1 & & & & & & \\
\hline Sabah & 0.606 & $(-0.049,1.26)$ & 0.07 & & & & \\
\hline West Malaysia & -0.584 & $(-0.951,-0.217)$ & 0.002 & -0.583 & $(-1.030,-0.136)$ & -2.562 & o.011 \\
\hline \multicolumn{8}{|l|}{ Gender } \\
\hline Male & 1 & & & & & & \\
\hline Female & 0.396 & $(0.032,0.76)$ & 0.033 & & & & \\
\hline \multicolumn{8}{|l|}{ Race } \\
\hline \multicolumn{8}{|l|}{ Malay } \\
\hline Chinese & 1.232 & $(0.777,1.687)$ & $<0.001$ & & & & \\
\hline Indian & -0.774 & $(-1.148,-0.4)$ & $<0.001$ & -0.752 & $(-1.154,-0.351)$ & -3.681 & $<0.001$ \\
\hline Others & -0.343 & $(-0.769,0.084)$ & 0.115 & -0.992 & $(-1.461,-0.522)$ & -4.15 & $<0.001$ \\
\hline
\end{tabular}

Religion

Islam

1

Hindu

$-0.705 \quad(-1.091,-0.320) \quad<0.001$

Christian

Others

0.378

(-0.012, 0.768)

0.058

0.265

$(-0.347,0.877)$

0.395

\section{Education level}

Pre-university and below

Undergraduate

$0.163 \quad(-0.203,0.529)$

0.382

1.055

$(0.636,1.474)$

4.946

$<0.001$ 
Table 7: (Continued)

\begin{tabular}{|c|c|c|c|c|c|c|c|}
\hline \multirow[t]{2}{*}{ Variables } & \multicolumn{3}{|c|}{ SLR $^{a}$} & \multicolumn{4}{|c|}{$\mathrm{MLR}^{\mathrm{b}}$} \\
\hline & $\boldsymbol{b}^{\mathrm{c}}$ & $(95 \% \mathrm{CI})$ & $P$ value & Adj. $b^{d}$ & $(95 \% \mathrm{CI})$ & $t$-stat & $P$ value \\
\hline $\begin{array}{l}\text { Postgraduate and } \\
\text { above }\end{array}$ & 0.759 & $(0.28,1.238)$ & 0.002 & 1.066 & $(0.558,1.574)$ & 4.119 & $<0.001$ \\
\hline \multicolumn{8}{|l|}{ Marital status } \\
\hline Unmarried & 1 & & & & & & \\
\hline Married & 0.551 & $(0.181,0.922)$ & 0.004 & & & & \\
\hline \multicolumn{8}{|l|}{ Employment } \\
\hline Unemployed & 1 & & & & & & \\
\hline Student & -0.411 & $(-0.777,-0.046)$ & 0.027 & & & & \\
\hline Employed (medical) & 0.806 & $(0.341,1.271)$ & 0.001 & 0.719 & $(0.272,1.167)$ & 3.161 & 0.002 \\
\hline $\begin{array}{l}\text { Employed (non-med- } \\
\text { ical_ }\end{array}$ & -0.193 & $(-0.582 .0 .196)$ & 0.331 & & & & \\
\hline $\begin{array}{l}\text { Total score of prac- } \\
\text { tice }\end{array}$ & 0.073 & $(0.039,0.107)$ & $<0.001$ & & & & \\
\hline $\begin{array}{l}\text { Total score of at- } \\
\text { titudes }\end{array}$ & 0.123 & $(0.095,0.151)$ & $<0.001$ & 0.11 & $(0.084,0.137)$ & 8.181 & $<0.001$ \\
\hline
\end{tabular}

Table 8: Factors associated with total score of attitudes towards COVID-19 among Malaysians ( $\mathrm{N}=571)$

\begin{tabular}{|c|c|c|c|c|c|c|c|}
\hline \multirow{2}{*}{ Variables } & \multicolumn{3}{|c|}{ SLR $^{a}$} & \multicolumn{4}{|c|}{ MLR $^{\mathbf{b}}$} \\
\hline & $b^{\mathbf{c}}$ & $(95 \% \mathrm{CI})$ & $P$ value & Adj. $b^{d}$ & $(95 \% \mathrm{CI})$ & $t$-stat & $P$ value \\
\hline Age (years) & 0.008 & $(-0.030,0.046)$ & 0.689 & & & & \\
\hline \multicolumn{8}{|l|}{ Monthly income } \\
\hline Less than $\mathrm{RM}_{5000}$ & 1 & & & & & & \\
\hline RM500o-RM9999 & 1.813 & $(0.521,3.105)$ & 0.006 & 1.704 & $(0.431,2.977)$ & 2.63 & 0.009 \\
\hline More than RMioooo & 0.818 & $(-1.571,3.206)$ & 0.502 & & & & \\
\hline \multicolumn{8}{|l|}{ Current residency } \\
\hline Sarawak & 1 & & & & & & \\
\hline Sabah & 0.966 & $(-0.832,2.763)$ & 0.292 & & & & \\
\hline West Malaysia & -0.09 & $(-1.105,0.925)$ & 0.862 & & & & \\
\hline \multicolumn{8}{|l|}{ Gender } \\
\hline Male & 1 & & & & & & \\
\hline Female & 1 & $(-0.004,2.005)$ & 0.051 & & & & \\
\hline \multicolumn{8}{|l|}{ Race } \\
\hline Malay & 1 & & & & & & \\
\hline Chinese & 1.997 & $(0.723,3.272)$ & 0.002 & & & & \\
\hline Indian & -0.484 & $(-1.529,0.561)$ & 0.363 & & & & \\
\hline Others & -0.259 & $(-1.436,0.918)$ & 0.666 & & & & \\
\hline \multicolumn{8}{|l|}{ Religion } \\
\hline Islam & 1 & & & & & & \\
\hline Hindu & -0.571 & $(-1.643,0.501)$ & 0.296 & & & & \\
\hline Christian & 0.82 & $(-0.255,1.896)$ & 0.135 & & & & \\
\hline Others & 0.95 & $(-0.735,2.635)$ & 0.269 & & & & \\
\hline
\end{tabular}


Table 8: (Continued)

\begin{tabular}{|c|c|c|c|c|c|c|c|}
\hline \multirow[t]{2}{*}{ Variables } & \multicolumn{3}{|c|}{$\mathbf{S L R}^{\mathrm{a}}$} & \multicolumn{4}{|c|}{$\mathbf{M L R}^{\mathbf{b}}$} \\
\hline & $\boldsymbol{b}^{\mathrm{c}}$ & $(95 \% \mathrm{CI})$ & $P$ value & Adj. $b^{d}$ & $(95 \% \mathrm{CI})$ & $t$-stat & $P$ value \\
\hline \multicolumn{8}{|l|}{ Education level } \\
\hline Pre-university and below & 1 & & & & & & \\
\hline Undergraduate & 0.717 & $(-0.29,1.724)$ & 0.163 & & & & \\
\hline Postgraduate and above & 0.09 & $(-1.241,1.421)$ & 0.894 & & & & \\
\hline \multicolumn{8}{|l|}{ Marital status } \\
\hline Unmarried & 1 & & & & & & \\
\hline Married & -0.152 & $(-1.18,0.875)$ & 0.771 & & & & \\
\hline \multicolumn{8}{|l|}{ Employment } \\
\hline Unemployed & 1 & & & & & & \\
\hline Student & 0.494 & $(-0.516,1.504)$ & 0.337 & 1.451 & $(0.463,2.439)$ & 2.885 & 0.005 \\
\hline Employed (medical) & 0.484 & $(-0.81,1.778)$ & 0.463 & & & & \\
\hline Employed (non-medical_ & -0.807 & $(-1.878,0.264)$ & 0.14 & & & & \\
\hline Total score of knowledge & 0.937 & $(0.723,1.15)$ & $<0.001$ & 0.822 & $(0.611,1.032)$ & 7.668 & $<0.001$ \\
\hline Total score of practice & 0.342 & $(0.251,0.434)$ & $<0.001$ & 0.278 & $(0.190,0.367)$ & 6.17 & $<0.001$ \\
\hline
\end{tabular}

Table 9: Factors associated with total score of practice towards COVID-19 among Malaysians (N=571)

\begin{tabular}{|c|c|c|c|c|c|c|c|}
\hline \multirow[t]{2}{*}{ Variables } & \multicolumn{3}{|c|}{$\mathbf{S L R}^{\mathbf{a}}$} & \multicolumn{4}{|c|}{ MLR $^{\mathbf{b}}$} \\
\hline & $b^{c}$ & $(95 \% \mathrm{CI})$ & Pvalue & Adj. $b^{d}$ & $(95 \% \mathrm{CI})$ & t-stat & Pvalue \\
\hline Age (years) & 0.043 & $(0.011,0.076)$ & 0.009 & & & & \\
\hline \multicolumn{8}{|l|}{ Monthly income } \\
\hline Less than $\mathrm{RM}_{5000}$ & 1 & & & & & & \\
\hline RM5000-RM9999 & 1.09 & $(-0.023,2.203)$ & 0.055 & & & & \\
\hline More than RMioooo & 1.198 & $(-0.851,3.248)$ & 0.251 & & & & \\
\hline \multicolumn{8}{|l|}{ Current residency } \\
\hline Sarawak & 1 & & & & & & \\
\hline Sabah & 1.038 & $(-0.516,2.593)$ & 0.19 & & & & \\
\hline West Malaysia & -0.895 & $(-1.770,-.020)$ & 0.045 & & & & \\
\hline \multicolumn{8}{|l|}{ Gender } \\
\hline Male & 1 & & & & & & \\
\hline Female & 1.775 & $(0.922,2.629)$ & $<0.001$ & 1.84 & $(1.016,2.664)$ & $4 \cdot 385$ & 0.003 \\
\hline \multicolumn{8}{|l|}{ Race } \\
\hline Malay & 1 & & & & & & \\
\hline Chinese & 1.971 & $(0.879,3.063)$ & $<0.001$ & 1.579 & $(0.54,2.618)$ & 2.984 & $<0.001$ \\
\hline Indian & -0.195 & $(-1.094,0.703)$ & 0.67 & & & & \\
\hline Others & 0.444 & $(-0.567,1.456)$ & 0.388 & & & & \\
\hline \multicolumn{8}{|l|}{ Religion } \\
\hline Islam & 1 & & & & & & \\
\hline Hindu & -0.172 & $(-1.094,0.750)$ & 0.714 & & & & \\
\hline Christian & 1.128 & $(0.206,2.050)$ & 0.017 & & & & \\
\hline Others & 1.47 & $(0.025,2.914)$ & 0.046 & & & & \\
\hline
\end{tabular}

\section{Education level}

Pre-university and below 
Table 9: (Continued)

\begin{tabular}{|c|c|c|c|c|c|c|c|}
\hline \multirow[t]{2}{*}{ Variables } & \multicolumn{3}{|c|}{$\mathbf{S L R}^{\mathbf{a}}$} & \multicolumn{4}{|c|}{$\mathbf{M L R}^{\mathrm{b}}$} \\
\hline & $\boldsymbol{b}^{\mathrm{c}}$ & $(95 \% \mathrm{CI})$ & Pvalue & Adj. $b^{d}$ & $(95 \% \mathrm{CI})$ & t-stat & Pvalue \\
\hline Undergraduate & -0.771 & $(-1.635,0.094)$ & 0.081 & & & & \\
\hline Postgraduate and above & 1.044 & $(-0.097,2.184)$ & 0.073 & & & & \\
\hline \multicolumn{8}{|l|}{ Marital status } \\
\hline Unmarried & 1 & & & & & & \\
\hline Married & 0.985 & $0.106,1.864$ & 0.028 & & & & \\
\hline \multicolumn{8}{|l|}{ Employment } \\
\hline Unemployed & 1 & & & & & & \\
\hline Student & -0.487 & $(-1.355,0.381)$ & 0.271 & & & & \\
\hline Employed (medical) & 1.851 & $0.749,2.952$ & 0.001 & 2.242 & $(1.185,3.299)$ & 4.167 & $<0.001$ \\
\hline Employed (non-medical_ & -0.905 & $(-1.824,0.014)$ & 0.054 & & & & \\
\hline $\begin{array}{l}\text { Total score of knowl- } \\
\text { edge }\end{array}$ & 0.41 & $0.218,0.602$ & $<0.001$ & & & & \\
\hline Total score of attitudes & 0.253 & $0.185,0.320$ & $<0.001$ & 0.223 & $(0.156,0.290)$ & 6.554 & $<0.001$ \\
\hline
\end{tabular}

